Characterization of ambient aerosols at the San Francisco International Airport using BioAerosol Mass Spectrometry

P. T. Steele, E. L. McJimpsey, K. R. Coffee, D. P.

Fergenson, V. J. Riot, H. J. Tobias, B. W. Woods, E. E. Gard, M. Frank

April 7, 2006

SPIE Defense\&Security Symposium

Kissimmee, FL, United States

April 17, 2006 through April 21, 2006 
This document was prepared as an account of work sponsored by an agency of the United States Government. Neither the United States Government nor the University of California nor any of their employees, makes any warranty, express or implied, or assumes any legal liability or responsibility for the accuracy, completeness, or usefulness of any information, apparatus, product, or process disclosed, or represents that its use would not infringe privately owned rights. Reference herein to any specific commercial product, process, or service by trade name, trademark, manufacturer, or otherwise, does not necessarily constitute or imply its endorsement, recommendation, or favoring by the United States Government or the University of California. The views and opinions of authors expressed herein do not necessarily state or reflect those of the United States Government or the University of California, and shall not be used for advertising or product endorsement purposes. 


\title{
Characterization of ambient aerosols at the San Francisco International Airport using BioAerosol Mass Spectrometry
}

\author{
Paul T. Steele ${ }^{* a}$, Erica L. McJimpsey ${ }^{\text {ab }}$, Keith R. Coffee ${ }^{\mathrm{a}}$, David P. Fergenson ${ }^{\mathrm{a}}$, Vincent J. Riot ${ }^{\mathrm{a}}$, \\ Herbert J. Tobias ${ }^{\mathrm{a}}$, Bruce W. Woods ${ }^{\mathrm{a}}$, Eric E. Gard ${ }^{\mathrm{a}}$, Matthias Frank ${ }^{\mathrm{a}}$ \\ ${ }^{a}$ Lawrence Livermore National Laboratory, 7000 East Ave., Livermore, CA, USA 94550 \\ ${ }^{\mathrm{b}}$ Univerity of California Davis, One Shields Ave, Davis, CA USA 95616
}

\begin{abstract}
The BioAerosol Mass Spectrometry (BAMS) system is a rapidly fieldable, fully autonomous instrument that can perform correlated measurements of multiple orthogonal properties of individual aerosol particles. The BAMS front end uses optical techniques to nondestructively measure a particle's aerodynamic diameter and fluorescence properties. Fluorescence can be excited at $266 \mathrm{~nm}$ or $355 \mathrm{~nm}$ and is detected in two broad wavelength bands. Individual particles with appropriate size and fluorescence properties can then be analyzed more thoroughly in a dual-polarity time-of-flight mass spectrometer. Over the course of two deployments to the San Francisco International Airport, more than 6.5 million individual aerosol particles were fully analyzed by the system. Analysis of the resulting data has provided a number of important insights relevant to rapid bioaerosol detection, which are described here.
\end{abstract}

Keywords: Fluorescence, mass spectrometry, bioaerosols, airport

\section{INTRODUCTION}

In 1347, a khan of the Golden Horde named Yannibeg attempted to wage biological war against the city of Kaffa using large airborne "particles" - he catapulted the corpses of plague victims over the city's walls. In 1940, Japanese forces abandoned human corpses in favor of a smaller delivery vehicle; they airdropped plague-infested fleas on the city of Ningbo. Following World War II, the Soviets made great progress in weaponizing plague directly. Today, a biological attack is unlikely to be signaled by corpses or even fleas falling from the sky. An attack may not be noticed at all until its victims become ill and show up at hospitals.

Diseases such as plague and anthrax can often be dealt with effectively if treatment is begun before symptoms appear ${ }^{1,2}$. This is not the case for all diseases however. The treatment of viral hemorrhagic fevers, for example, is primarily only supportive in nature ${ }^{3}$; little can be done to combat the viruses directly. The detection of a biological weapon within the order of a day does have value but it is limited. Ideally, biological detection should occur within minutes or even seconds so that human exposure could be altogether avoided or at least minimized. It is good to "detect to treat" but it is even better to "detect to warn".

Fluorescence based bioaerosol detectors such as BAWS can rapidly analyze aerosols and signal that an agent might be present, but the false alarm rates of existing detectors are generally considered too high to be widely useful. If it is known with high certainly that an agent is present, extraordinary actions can be justified. Large facilities or perhaps even small cities could be evacuated. Willingness to take such actions based solely on the output of a detector will be greatly reduced if not altogether eliminated, however, if that detector false alarms once a week, once a month or perhaps even just once per year.

The San Francisco International Airport (SFO) is a single but nonetheless important example of a large facility where the ability to rapidly and accurately detect the presence of a biological warfare agent, or even a naturally occurring "agent", is desired. The performance of any detector depends critically upon the environment in which it is deployed, yet surprising little is known about the ambient aerosols at SFO or any number of other important locations. A BioAerosol

* psteele@1lnl.gov; phone 1925 422-5239; fax 1925 424-2778 
Mass Spectrometry (BAMS) system developed at Lawrence Livermore National Laboratory (LLNL) was thus deployed on two occasions to characterize the ambient aerosols at the airport. The data from these deployments is being analyzed to help the BAMS system itself, as well as other detection systems, to operate more effectively in such environments in the future.

\section{INSTRUMENTS AND DEPLOYMENTS}

BAMS is an instrument that was built to rapidly characterize individual aerosol particles falling in the respirable size range $(1-10 \mu \mathrm{m})^{4,5}$. At SFO, the BAMS system was placed, along with other sensors and detectors, in an aerosol test bed operated by Sandia National Laboratory (SNL) and supported by the Department of Homeland Security's (DHS) PROACT program. BAMS operated there largely unattended for multiple weeks and collected a large volume of valuable data as will be described.

\subsection{The BAMS system}

To maximize the sensitivity of the BAMS system (Fig. 1 and Fig. 2), a virtual impactor was employed to increase the concentration of particles in the sampled air stream. A commercial system from Mesosystems was used during both deployments to enrich the particle content by 30-100× over most of the size range of interest. The BAMS system itself draws air and entrained aerosol particles through its inlet into vacuum at a rate of $\sim 1 \mathrm{~L} / \mathrm{min}$. During the first deployment, a low efficiency converging nozzle ${ }^{6}$ was used. For the second deployment, a highly efficient aerodynamic lens stack was fielded, which was custom designed by the BAMS group. In either case, a supersonic expansion into vacuum focuses the sampled aerosol particles into a vertically orientated beam that passes downward through one or more stages of differential pumping, through a sizing region (which acts as an additional pumping stage), through a fluorescence stage, and finally into the ion source region at the center of the dual polarity mass spectrometer. The expansion imparts each particle with a velocity dependent on its aerodynamic diameter; small particles travel faster than larger particles. An aerosol particle that has been properly focused and accelerated crosses three $\mathrm{CW}$ laser beams in the sizing region causing three bursts of scattered light that are detected by separate channel multiplier tubes. The times at which the scattered light bursts occur are used to determine the particle's position, velocity and, with proper calibration, aerodynamic diameter ${ }^{7,8}$. (The magnitude of the scattered light bursts are not used to estimate particle size.) Once the particle's position and

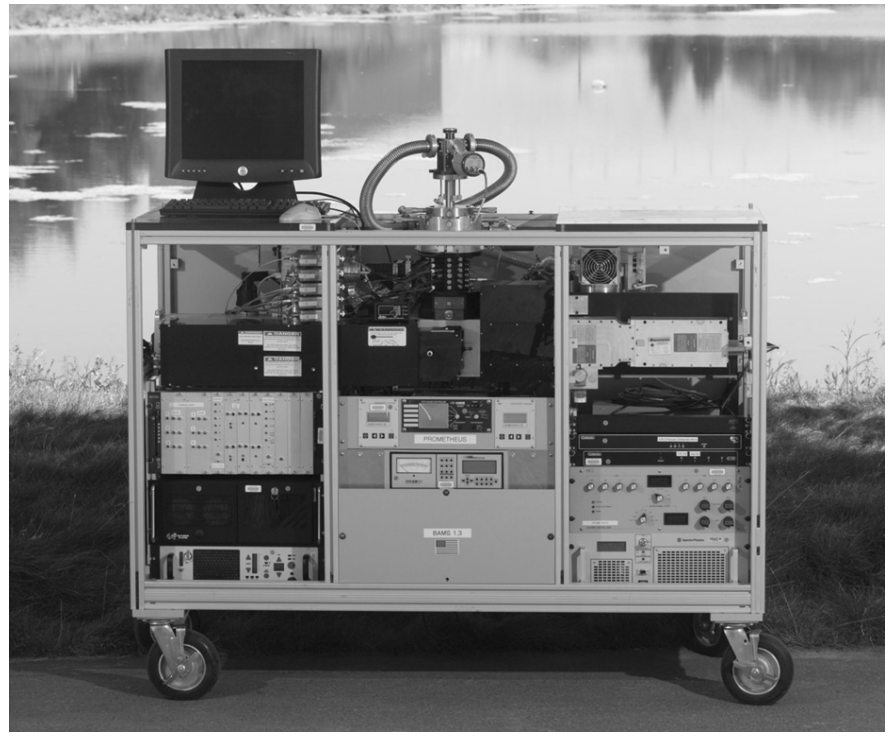

Fig. 1. An image of a BAMS system ready for deployment. The system can easily be transported from location to location and requires only electricity to operate. The virtual impactor is not shown. velocity are known, the system predicts when the particle will reach subsequent stages of the instrument so that the pulsed lasers and other electronics can be triggered appropriately.

After the sizing and tracking stage, particles pass through a stage that probes their intrinsic fluorescence properties. During the first deployment, the stage employed a J40-BL6S-266Q laser from Spectra Physics, which is a Q-switched, frequency quadrupled (i.e. 266nm) Nd:YAG laser. The excitation pulse energy was set at $\sim 7 \mu \mathrm{J}$ and the beam was focused to a spot $\sim 500 \mu \mathrm{m}$ in diameter. Using an ellipsoidal mirror and a lens approximately $85 \%$ of the excited fluorescence was collected. Two separate photomultiplier tubes monitored the fluorescence in two broad wavelength bands. (Elastically scattered excitation light was carefully filtered out and was not directly monitored.) The "UV" fluorescence band covered wavelengths between 290 and $400 \mathrm{~nm}$. The "visible" band covered wavelengths of $400 \mathrm{~nm}$ and greater. During the second deployment, a tripled (i.e. 


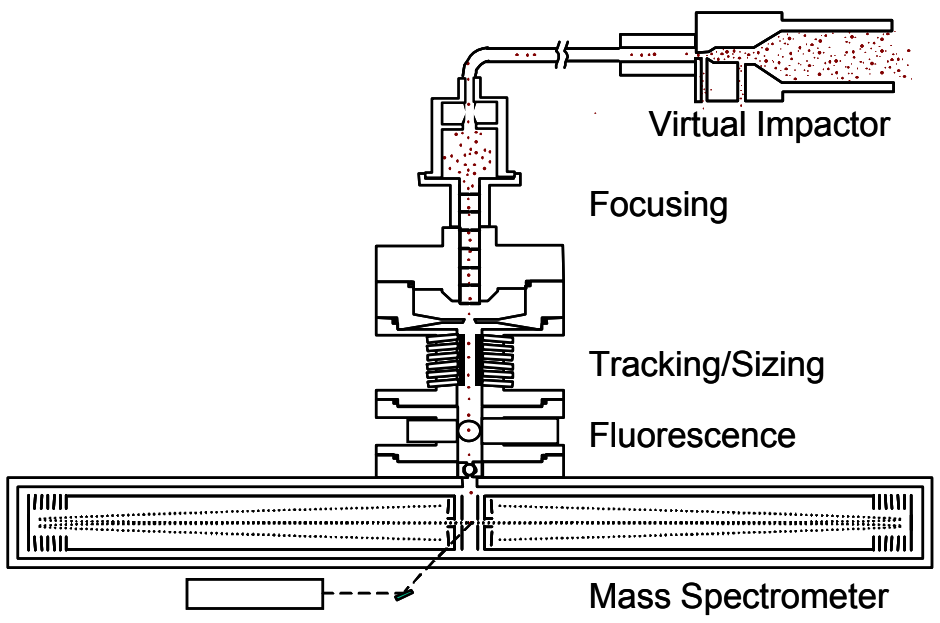

Fig. 2 A schematic of the BAMS instrument.
$355 \mathrm{~nm}$ ) version of the same basic laser was used. The excitation pulse energy was increased and the collection bands were shifted. It should be noted that since scatter was not monitored, it was impossible to differentiate a fluorescent particle that was either weakly excited or whose fluorescence was inefficiently collected from a truly nonfluorescent particle.

After passing through the fluorescence stage, the particles arrive at the ion source region of the dualpolarity mass spectrometer. The desorption/ionization (DI) laser is a Big Sky Laser Technologies Ultra with an integrated fourth harmonic package. This is a Q-switched, frequency-quadrupled Nd:YAG laser system that emits pulses with a wavelength of $266 \mathrm{~nm}$ and a pulse length of $\sim 6 \mathrm{~ns}$. (The $266 \mathrm{~nm}$ wavelength is particularly useful since it is nearly coincident with absorption peaks in dipicolinic acid ${ }^{9}$ and several of the amino acids present in bacterial spores.) External optics were used to produce a roughly flattop beam $\sim 400 \mu \mathrm{m}$ in diamter ${ }^{10}$. The pulse energy was set to $\sim 0.3 \mathrm{~mJ}$. In dirty environments with high concentrations of background particles, the DI laser can be selectively fired at particles with agent-like fluorescent properties to yield greater detection sensitivity. During the two deployments, however, no such subset selection was made.

A single pulse from the DI laser both desorbs and ionizes molecules from individual aerosol particles. The ionized molecules are extracted from the single source region into effectively two opposing reflectron time-of-flight mass spectrometers ${ }^{11,12}$. One spectrometer analyzes positive ions and the other analyzes negative ions. For both polarities, a two-stage, static extraction potentia $1^{13}$ is used. After the ions are extracted from the source, they traverse a drift region and are then reflected back towards the source. When properly configured, the reflectron helps correct for the initial spread of ion energies imparted by the DI event. After traversing the drift region a second time, the ions are detected with microchannel plates (MCPs) ${ }^{14}$ located on either side of the source region. Since all ions are imparted with the same amount of energy per charge (and virtually all are singly charged), small ions have higher velocities and cover a fixed distance in less time than larger ions. This is, of course, the well-known basis of time-of-flight mass spectrometry. The data acquisition (DAQ) system records the current (or more precisely the voltage) generated by the MCPs every $2 \mathrm{~ns}$ with 8-bits of precision for $60 \mu$ s producing 30,000 data points per polarity $(60,000$ data points for the full dual-polarity mass spectrum). For each particle, the raw mass spectrum, fluorescence data, size and several other parameters are saved to disk where they can be instantly retrieved for automated real-time identification or stored for later analysis.

Decreasing numbers of particles are generally analyzed by each subsequent stage of the instrument both because of imperfect focusing and because of various speed limitations (e.g. finite repetition rate lasers). The BAMS data shown in section 3 is based purely on those particles fully analyzed by the system (i.e. those from which size, fluorescence and mass spectral data have all been acquired). A far greater number of particles were partially analyzed.

\subsection{SFO test bed}

The San Francisco International Airport is located southeast of its namesake on the west side of the San Francisco Bay. In 2004, more that 32 million total passengers were enplaned and deplaned. More than 7.5 million of these were international travelers with $48 \%$ of internal traffic going to Asia and $28 \%$ to Europe. The international terminal itself occupies over 2.5 million square feet and is one of the largest in North America. It is a relatively new and clean facility with a modern heating, ventilation and air conditioning (HVAC) system. Within that HVAC system, SNL operates a test bed for the study of ambient aerosols funded by DHS. 
The test bed is located in one of the air handlers on the penthouse floor of the international terminal. This is above the departure hallway, which contains several restaurants and shops and is itself above the actual departure level. It draws outside air through a filter bank, circulates it through the terminal and then vents it back to the outside. Air can be recirculated to reduce heating or cooling costs, but this was not done during the deployments. The test bed itself is located in a room (or really a large duct) just prior to the point where the air drawn through the terminal is vented to the outdoors. Consequently, the aerosols measured in the test bed should be representative of those found within the terminal itself rather than those without. The airflow within the test bed was very turbulent.

\subsection{Deployment details}

Deployment of the BAMS system is surprisingly easy. The system was pushed into the back of a truck at LLNL, driven to the airport, unloaded, plugged in and working within a matter of hours. The BAMS instrument was not placed directly in the test bed (i.e. air duct) because of limited space. Instead a virtual impactor was placed within the test bed and a sampling line was run to the BAMS system located immediately outside. The sampling line of course introduces some sampling biases, but absolute quantification of the concentration of constituents in the background aerosol was not the primary goal of the deployments. An aerodynamic particle sizer (APS) from TSI Inc. was placed within the test bed to accurately monitor the total aerosol concentration.

The BAMS system is remotely operable and will automatically send warnings by email when performance problems are detected. Remote operation and monitoring of the system at SFO proved to be problematic, however, due purely to network complications related to the multiple firewalls operated by LLNL, SNL and SFO. Fortunately, once the BAMS system was in place and properly tuned, it needed only minimal maintenance and supervision. Approximately once per week, the virtual impactor and the particle inlet were cleaned. No large particle filter was used which might have further reduced the need for cleaning.

Several other instruments were also at the test bed during our deployments. SNL built and deployed a "puffer" system to spectrally resolve the fluorescence of individual aerosol particles and then subsequently collect interesting particles for later analysis as part of a collaboration with Pan and coworkers ${ }^{15,16}$. A BAWS system from General Dynamics and two BioLert systems from Hach Homeland Security Technologies were present. Other instruments analyzed bulk samples or collected and archived bulk samples for later analysis. Because of proprietary issues, however, our findings directly concerning the performance of other detectors will not be discussed here.

The first deployment of BAMS to SFO began in December of 2004 and lasted approximately 7 weeks during which nearly one million particles were fully analyzed (resulting in over 60 gigabytes of raw data). The second deployment began in June of 2005, after several significant instrumental modifications had been implemented, and lasted approximately 5 weeks. Because of improved particle focusing, over 5.5 million particles were fully analyzed. Data from the first deployment has been most thoroughly analyzed and will be the focus of discussion below. All findings from the second deployment are consistent with the conclusions presented here.

\section{DATA AND RESULTS}

BAMS measures the size of individual aerosol particles. Although size cannot be expected to reveal the exact identity of a given particle, it is a useful and perhaps under appreciated bit of information. Fig. 3a shows the average size distribution of particles measured by an APS at SFO during the first deployment. As is typical in most environments, the vast majority of particles are relatively small (i.e. $<1 \mu \mathrm{m}$ ). The mean total concentration measured was $\sim 16,000$ particles/liter. The mean concentrations of particles with diameters larger than $0.75,1.0$ and $1.15 \mu \mathrm{m}$ were 4,500, 520 and 260 particles/liter respectively. This is significant because a detector capable of enforcing a strict lower size limit on the particles it sampled could have reduced the number of background particles it analyzed by more than a factor of 17 simply by moving the lower sampling limit from $0.75 \mu \mathrm{m}$ to $1.15 \mu \mathrm{m}$. Fig. 3b shows the particle size distribution for a Bacillus spore solution aerosolized using a Sono-Tek nozzle in a laboratory at LLNL (not at SFO). Most particles contain more than a single spore and are larger than $1.15 \mu \mathrm{m}$. If a simple detector had been deployed at the airport that 


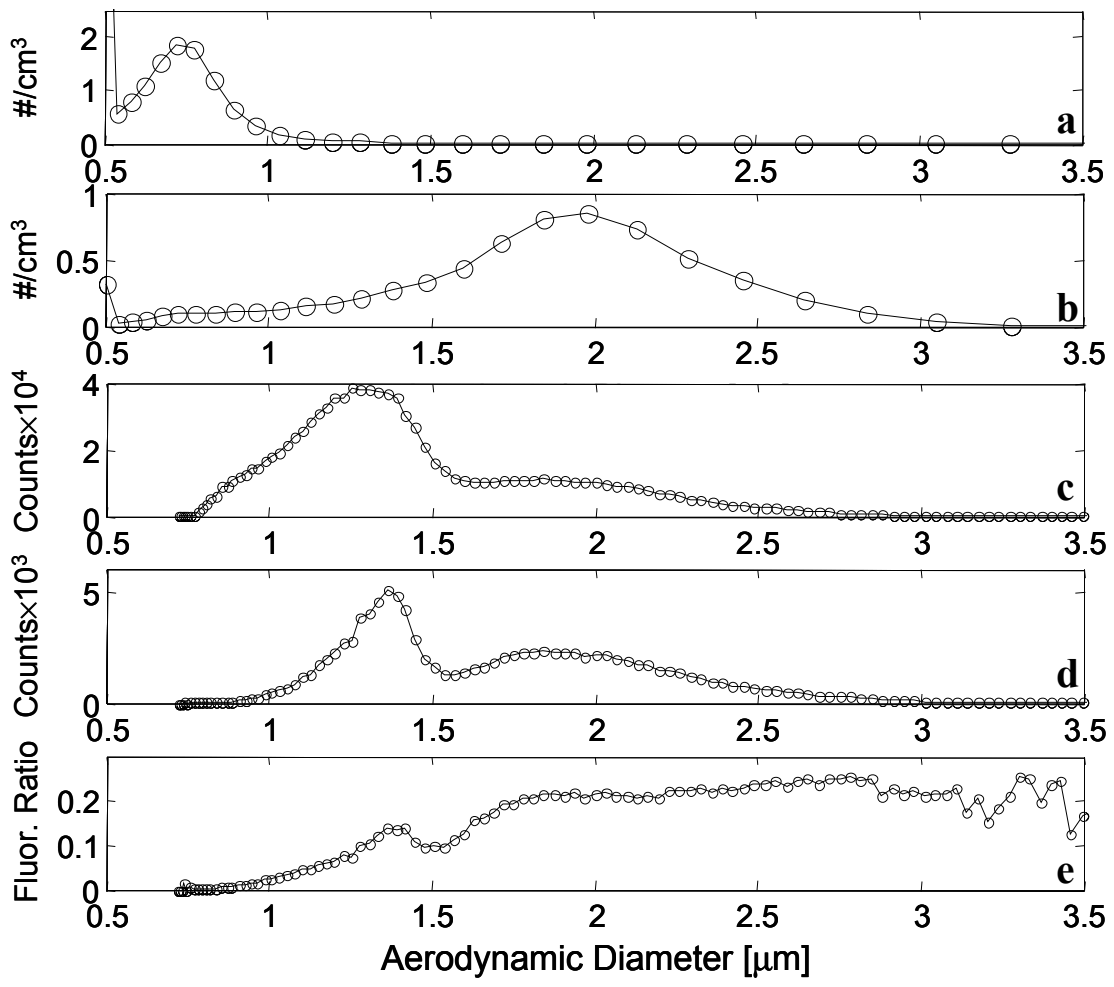

Fig. 3. a) APS measured mean size distribution of particles at SFO. The first data point (offscale) represents all measured particles $<0.52 \mu \mathrm{m}$. b) APS measured size distributions of Bacillus spore particles aerosolized with a Sono-Tek aerosol generator in a lab at LLNL. c) The total number of particles analyzed by BAMS at SFO. d) The number of fluorescence particles analyzed by BAMS. e) The ratio of fluorescing to total particle counts measured by BAMS.

The regions shown were chosen by eye to simplify further discussion (it is diffich rather clear minima between Region 1 and 2). Region 1 contains $6 \%$ of all particles. Region 2 contains $5 \%$ and region 3

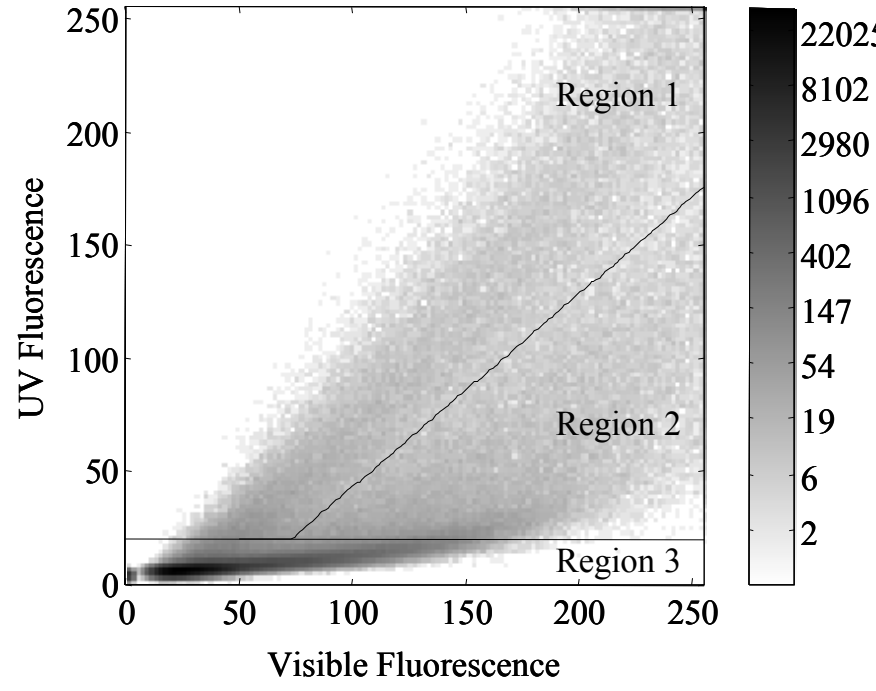

Fig. 4. Fluorescence distribution of $\sim 1$ million particles analyzed during the first SFO deployment of BAMS. Note the highly nonlinear color scale. sounded an alarm when the concentration of $>1.15 \mu \mathrm{m}$ particles exceeded 1000 particles/liter, for example, it would only have had a false alarm rate on the order of $1 /$ day and would have had a very high probability of detection in many attack scenarios. Size is a useful quantity.

The size distribution of the $\sim 1$ million particles fully analyzed by BAMS during its first deployment is shown in Fig. 3c. The inlet system was designed to preferentially sample particles falling within the respirable size range. As can easily be seen, much but not all of the small particle background has been avoided. The remaining small particles could have been ignored after the tracking stage (which is capable of handling far more particles than subsequent stages of the instrument), but this was not felt to be necessary.

After a particle's size has been determined by BAMS, the particle is probed in the fluorescence stage. Fig. 4 shows a 2D plot of the fluorescence data gathered from the fully analyzed particles. There are many equally valid ways of dividing the plot into regions. contains $89 \%$. Region 1 is of particular interest because it contains particles with fluorescence properties similar to those observed for fluorescent Bacillus spores. Some spores produce little measurable fluorescence and fall in the left part of region 3, but there are so many other particle types that fall in this same area that it is not particularly useful. Although the addition of a scattering channel might enable some of the background particle types falling into region 1 to be differentiated from agent, it is not surprising that detectors based purely upon $266 \mathrm{~nm}$ excitation can have difficulty obtaining very low false alarm rates.

Fig. 3d shows the size distribution of "fluorescent" particles (which are defined here as any particle falling into region 1 or 2). As expected, size and fluorescence are not entirely independent. Fig. 3e shows more clearly that the ratio of fluorescing to total particles increases with aerodynamic diameter. This certainly makes sense; to first order fluorescence should be proportional to the amount of energy absorbed, which 
in turn should be proportional to the particle's surface area or volume. Nonetheless, other factors influence the ratio as well. The chemical composition of small and large particles is not identical. Size dependent particle focusing may also exert some influence. Perhaps more important, however, is the seemingly opposite observation that virtually any sized particle can have fluorescence properties matching those of virtually any other sized particle (differences are only seen on average). Placing a sharp requirement on fluorescence properties (e.g. defining a specific threat box) is in no way equivalent to enforcing a strict size requirement. Size provides information complementary to that offered by fluorescence alone (even fluorescence supplemented with scattering information).

Far more useful than either size or fluorescence, the great strength of BAMS is its dual-polarity, single-particle mass spectrometer. The mass spectra of particles falling in each fluorescence region were isolated and then clustered to reveal which "spectral types" were most common in each region (this is similar in certain respects to the analysis in one of our earlier papers ${ }^{4}$ ). Fig. 5 shows the most common types and an average Bacillus spore spectrum (measured at LLNL) for comparison. None of the common spectral types appear similar to the spore spectrum or to other biological spectra with which the authors are familiar. More details on biological particles at SFO can be found in our accompanying paper "Detection of Biological Particles in Ambient Air using Bio-Aerosol Mass Spectrometry". Perhaps our most important conclusion reached therein is that the concentration of airborne spores and cells is very low within the SFO terminal. It would seem that some fluorescence based sensors false alarm not because of an inability to differentiate closely related biological species, but rather because of an inability to differentiate quite distinct types of particles. This is actually encouraging because it would seem that there is significant potential for the reduction of false alarms without having to resort to methods such as PCR.

A very important topic that has not yet been addressed is the dynamic nature of the environment. If background aerosols were static, it would be very easy to build a very good bioaerosol detector. Fig. 6 shows the number of particles analyzed by BAMS falling in each of the three fluorescence regions every five minutes for forty days. Perhaps the most distinctive feature of the data is the clear diurnal cycle apparent in the region 1 trace (Fig. 6a). A power spectrum of the region 1 data reveals a clear spike at 1/day along with spikes at higher harmonics, but there does not seem to be a clear frequency component responsible for the finer structure seen within the diurnal cycle. A diurnal cycle is not at all clear in the region 3 trace (Fig. 6c), which represents the vast bulk of analyzed particles. As might be expected, the region 2 trace (Fig. 6b) appears intermediate in character between the other two. One of the most important consequences of the largely independent variations in the region 1 and region 3 populations is that the fraction of region 1 particles can vary widely,

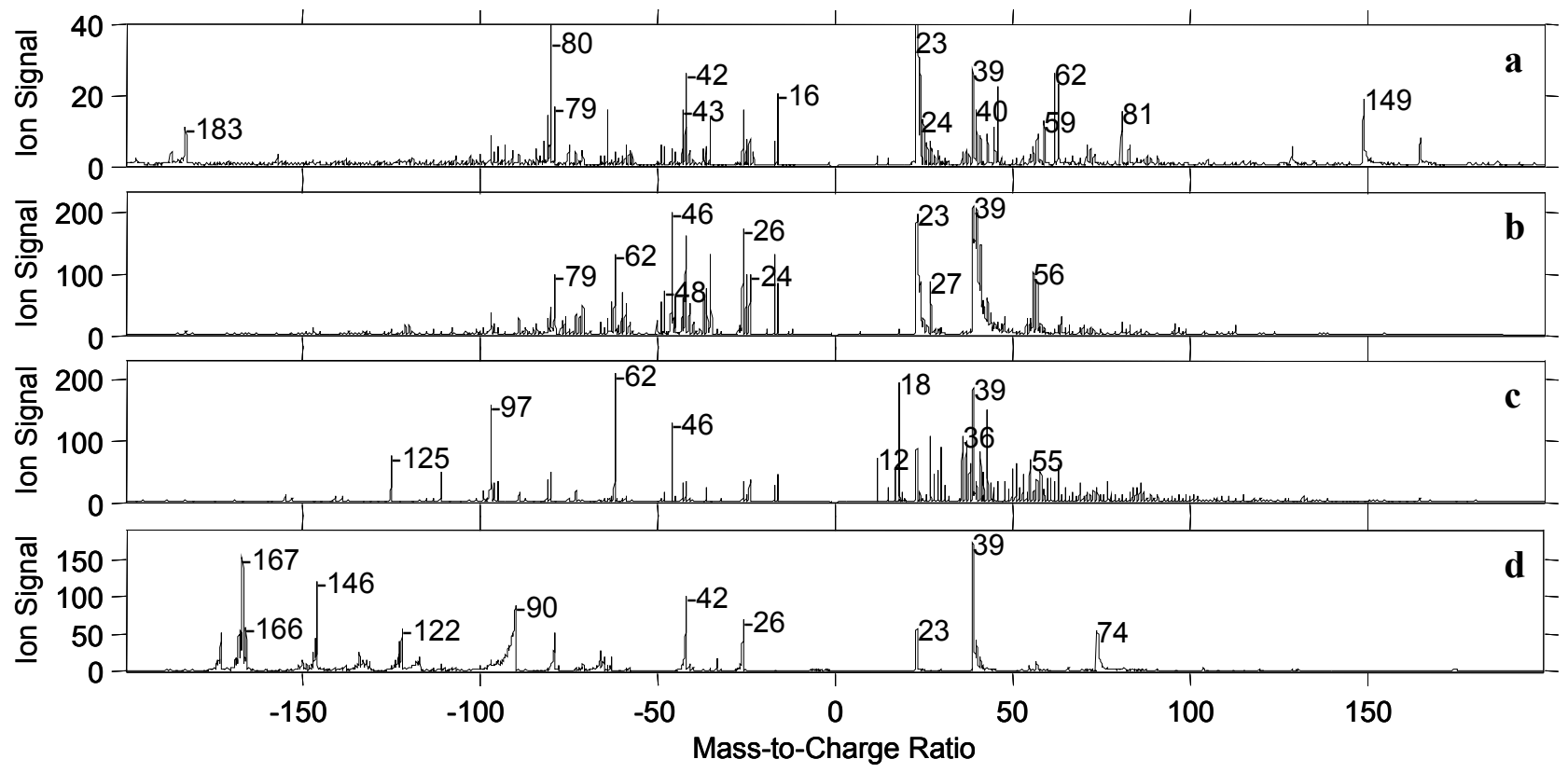

Fig. 5 Typical mass spectra (averaged) from each of the fluorescent regions: a) region 1, b) region 2 and c) region 3. d) An average spore spectrum collected on a different BAMS instrument is shown for comparison. The spectra from the fluorescent regions do not look similar to the spore spectrum or to other biological spectra with which the authors are familiar. 


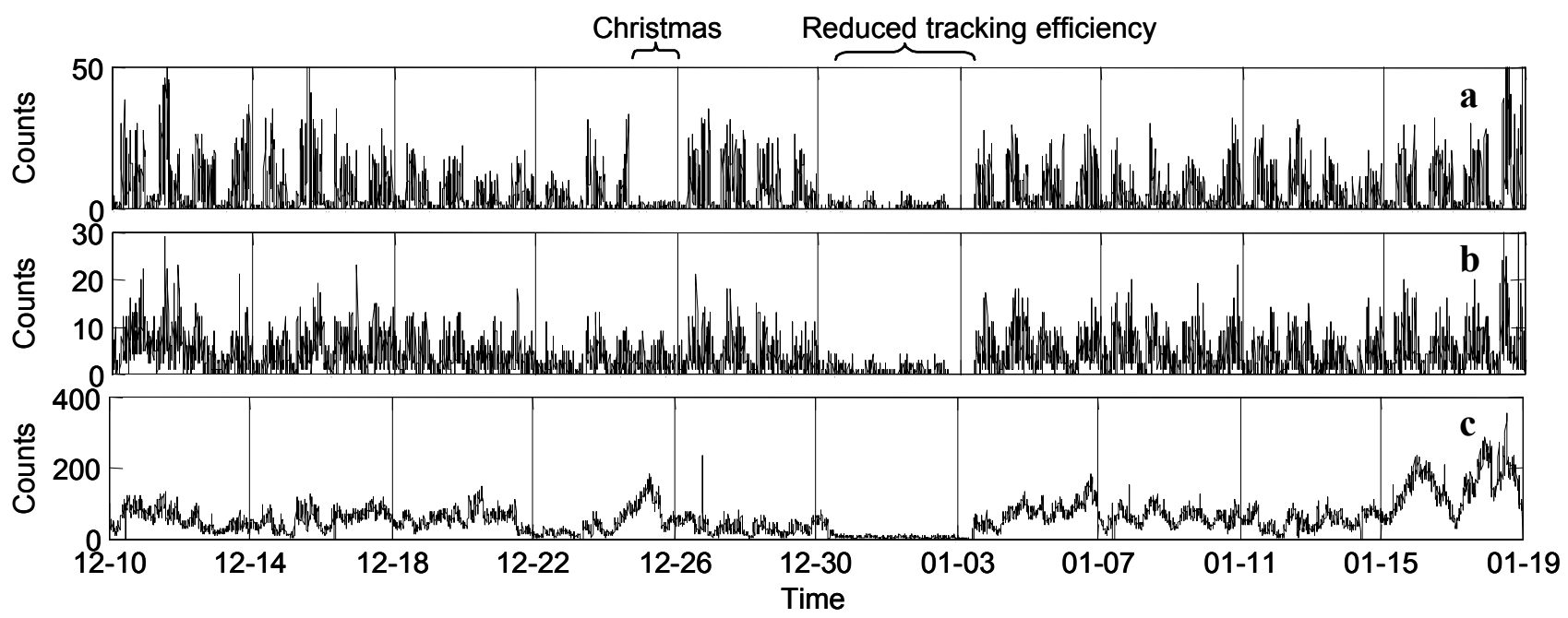

Fig. 6 The number of particles fully analyzed by BAMS in sequential 5 minute periods falling in a) region 1, b) region 2 and c) region 3. Note the clear diurnal cycle present in the region 1 data but absent in the region 3 data. A large fiber lodged in the tracking stage shortly after Dec. 30 and a problem was evident over the network, but because of the holidays we were unable to access the instrument until three days had elapsed.

rapidly and seemingly randomly. Any fluorescence-based detector must be capable of rapid response to the ambient background in order to maintain acceptable performance. Even with careful tracking of background variations, it is interesting to note that alarms sounded during certain parts of the day may be fundamentally more reliable than those sounded at other times.

A few other features within the time traces merit comment. Christmas day (Dec. 25) was unique. Fig. 6c shows that the total particle count spiked relative to surrounding days, but Fig. 6a shows a striking absence of counts in region 1 . The absence of region 1 particles may well be related to the fact that the restaurants within the terminal were closed for the holiday. That does not, however, explain why total particle counts increased. The absence of particles observed following Dec. 30 is well understood. A large fiber became lodged in the tracking stage and severely degraded the instrument's performance. (No large particle filter was used when sampling particles.) This drop in performance was rapidly noticed over the network connection, but access to the instrument wasn't possible for three days because of the holidays. The problem was rapidly fixed once access was possible.

The mass spectra associated with a number of transient fluorescent events have been analyzed. (These events represent some of the fine structure seen within the diurnal cycle in Fig. 6a.) It is not surprising that certain types of particles are almost always present. Other particle types, however, may be almost completely absent, suddenly spike in concentration and then suddenly disappear for a long period of time. Considering all the activities going on in the airport, this is certainly not surprising, but it is a significant fact that must be recognized. Unfortunately, this means that it is unwise to place a detector within an environment, run it for a few hours or days and then use statistical analyses to extrapolate out to some low number of false alarms expected per month or year. Unless a detector has been deployed for months or years, predictions of false alarms occurring once a month or year cannot be fully trusted; the detector simply cannot be expected to have experienced a sufficient range of environmental variation.

Finally, several controlled releases of Visolite, a harmless aerosol tracer material used for leak detection in air ducts, were carried out in different portions of the terminal to determine transport times to the test bed. In some cases, the time for the Visolite cloud to reach the test bed was significant. Clearly, it is important to consider this delay, as well as other factors, before setting specific performance requirements and specific concepts of operation for a future detector or detector system intended for actual protection of the airport. A response time of seconds may be ideal, but a response time of minutes might be adequate for many scenarios. Better sensitivity or a reduced false alarm rate might be more beneficial than a faster response in some scenarios. On a related note, it should be asked whether it is truly optimal to place a detector within the air handler or not. Such a placement is attractive in that it allows a large volume of aerosol to 
be effectively sampled by a single detector. A potential alternative, however, would be to place more numerous and cheaper detectors directly within the terminal. This might significantly reduce response times, but it could also increase the overall false alarm rate. (An individual detector may only false alarm once per month, but if 30 of them must be used, there will be a false alarm once per day on average.) Clearly, the very purpose of the detector must be considered and defined. Is the detector intended to detect to warn, detect to treat, or perhaps simply to prevent the spread of a release throughout a facility? Work is needed to find an optimal balance of the many tradeoffs involved and to develop meaningful bioaerosol detector requirements and deployment strategies.

\section{CONCLUSIONS}

BAMS is a powerful tool for the characterization of ambient aerosols. Particle size is a very simple yet effective bit of data for removing a great deal of the ambient background from subsequent analysis. Size, however, is not capable by itself of providing any type of accurate particle identification. Fluorescence provides a great deal of additional information, but a significant fraction of nonbiological particles at SFO still have spore or agent-like fluorescence. Mass spectrometry provides an incredible wealth of knowledge, but it comes at the cost of a larger more expensive instrument with a need for vacuum. BAMS clearly has an important role to play as a bioaerosol detector (using even a very crude alarm algorithm, it would not have triggered a false alarm for spores or vegetative cells at any point during it's seven week deployment), but there is also a role to be played by cheaper and smaller detectors. Those detectors must, however, be able to adapt to a highly dynamic environment like that at SFO. Fortunately, in an environment like SFO, the need to differentiate biological species does not seem necessary to obtain a low false alarm rate. The San Francisco airport is, however, a single facility and a unique environment. Many others need to be studied. Beyond simply quantifying what is naturally in the air, studies need to be undertaken to understand just how well a detector must perform and how it should be deployed. What is an acceptable sensitivity, false alarm rate, response time, size and cost? Is it better to have a few sophisticated detectors or a larger number of cheaper detectors? Where should the detectors be placed? Certainly, there is work to be done.

\section{ACKNOWLEDGMENTS}

This work was performed under the auspices of the U.S. Department of Energy by University of California, Lawrence Livermore National Laboratory under Contract W-7405-Eng-48. The deployments were funded by the Department of Homeland Security. The development of BAMS has largely been funded by the Department of Defense's Technical Support Working Group and Defense Advanced Research Projects Agency.

\section{DISCLAIMER}

This document was prepared as an account of work sponsored by an agency of the United States Government. Neither the United States Government nor the University of California nor any of their employees, makes any warranty, express or implied, or assumes any legal liability or responsibility for the accuracy, completeness, or usefulness of any information, apparatus, product, or process disclosed, or represents that its use would not infringe privately owned rights. Reference herein to any specific commercial product, process, or service by trade name, trademark, manufacturer, or otherwise, does not necessarily constitute or imply its endorsement, recommendation, or favoring by the United States Government or the University of California. The views and opinions of authors expressed herein do not necessarily state or reflect those of the United States Government or the University of California, and shall not be used for advertising or product endorsement purposes.

\section{REFERENCES}

Inglesby, T. V.; O'Toole, T.; Henderson, D. A.; Bartlett, J. G.; Ascher, M. S.; Eitzen, E.; Friedlander, A. M.; Gerberding, J.; Hauer, J.; Hughes, J.; McDade, J.; Osterholm, M. T.; Parker, G.; Perl, T. M.; Russell, P. K.; Tonat, K., "Anthrax as a biological weapon, 2002 - Updated recommendations for management", JAMA-J. Am. Med. Assoc., 287, 2236-2252, 2002.

Inglesby, T. V.; Dennis, D. T.; Henderson, D. A.; Bartlett, J. G.; Ascher, M. S.; Eitzen, E.; Fine, A. D.; Friedlander, A. M.; Hauer, J.; Koerner, J. F.; Layton, M.; McDade, J.; Osterholm, M. T.; O'Toole, T.; Parker, 
G.; Perl, T. M.; Russell, P. K.; Schoch-Spana, M.; Tonat, K., "Plague as a biological weapon - Medical and public health management", JAMA-J. Am. Med. Assoc., 283, 2281-2290, 2000. Borio, L.; Inglesby, T.; Peters, C. J.; Schmaljohn, A. L.; Hughes, J. M.; Jahrling, P. B.; Ksiazek, T.; Johnson, K. M.; Meyerhoff, A.; O'Toole, T.; Ascher, M. S.; Bartlett, J.; Breman, J. G.; Eitzen, E. M.; Hamburg, M.; Hauer, J.; Henderson, A.; Johnson, R. T.; Kwik, G.; Layton, M.; Lillibridge, S.; Nabel, G. J.; Osterholm, M. T.; Perl, T. M.; Russell, P.; Tonat, K., "Hemorrhagic fever viruses as biological weapons - Medical and public health management", JAMA-J. Am. Med. Assoc., 287, 2391-2405, 2002.

(4) Steele, P. T.; Tobias, H. J.; Fergenson, D. P.; Pitesky, M. E.; Horn, J. M.; Czerwieniec, G. A.; Russell, S. C.; Lebrilla, C. B.; Gard, E. E.; Frank, M., "Laser power dependence of mass spectral signatures from individual bacterial spores in bioaerosol mass spectrometry", Anal. Chem., 75, 5480-5487, 2003.

(5) Fergenson, D. P.; Pitesky, M. E.; Tobias, H. J.; Steele, P. T.; Czerwieniec, G. A.; Russell, S. C.; Lebrilla, C. B.; Horn, J. M.; Coffee, K. R.; Srivastava, A.; Pillai, S. P.; Shih, M. T. P.; Hall, H. L.; Ramponi, A. J.; Chang, J. T.; Langlois, R. G.; Estacio, P. L.; Hadley, R. T.; Frank, M.; Gard, E. E., "Reagentless detection and classification of individual bioaerosol particles in seconds", Anal. Chem., 76, 373-378, 2004.

(6) Johnston, M. V., "Sampling and analysis of individual particles by aerosol mass spectrometry", J. Mass Spectrom., 35, 585-595, 2000.

(7) Salt, K.; Noble, C. A.; Prather, K. A., "Aerodynamic particle sizing versus light scattering intensity measurement as methods for real time particle sizing coupled with time-of-flight mass spectrometry", Anal. Chem., 68, 230-234, 1996.

(8) Noble, C. A.; Prather, K. A., "Real-time measurement of correlated size and composition profiles of individual atmospheric aerosol particles", Environ. Sci. Technol., 30, 2667-2680, 1996.

(9) Nudelman, R.; Bronk, B. V.; Efrima, S., "Fluorescence emission derived from dipicolinic acid, its sodium, and its calcium salts", Appl. Spectrosc., 54, 445-449, 2000.

(10) Steele, P. T.; Srivastava, A.; Pitesky, M. E.; Fergenson, D. P.; Tobias, H. J.; Gard, E. E.; Frank, M., "Desorption/ionization fluence thresholds and improved mass spectral consistency measured using a flattop laser profile in the bioaerosol mass spectrometry of single Bacillus endospores", Anal. Chem., 77, 7448-7454, 2005.

(11) Karataev, V. I.; Mamyrin, B. A.; Shmikk, D. V., "New method for focusing ion bunches in time-of-flight mass spectrometers", Soviet Physics - Technical Papers, 16, 1177-1111-1179, 1972.

(12) Mamyrin, B. A.; Karataev, V. I.; Shmikk, D. V.; Zagulin, V. A., "The mass-reflectron, a new nonmagnetic time-of-flight mass spectrometer with high resolution", Soviet Physics - JETP, 37, 45-48, 1973.

(13) Wiley, W. C.; McLaren, I. H., "Time-of-flight mass spectrometer with improved resolution", The Review of Scientific Instruments, 26, 1150-1157, 1955.

(14) Wiza, J. L., "Microchannel Plate Detectors", Nuclear Instruments \& Methods, 162, 587-601, 1979.

(15) Pan, Y. L.; Boutou, V. E.; Bottiger, J. R.; Zhang, S. S.; Wolf, J. P.; Chang, R. K., "A puff of air sorts bioaerosols for pathogen identification", Aerosol Sci. Technol., 38, 598-602, 2004.

(16) Pan, Y. L.; Cobler, P.; Rhodes, S.; Potter, A.; Chou, T.; Holler, S.; Chang, R. K.; Pinnick, R. G.; Wolf, J. P., "High-speed, high-sensitivity aerosol fluorescence spectrum detection using a 32-anode photomultiplier tube detector", Rev. Sci. Instrum., 72, 1831-1836, 2001. 